\title{
Evaluating the outcome of severe head injury with transcranial Doppler ultrasonography
}

\author{
José A. Moreno, M.D., Eduard Mesalles, M.D., Juan Gener, M.D., \\ Antonio Tomasa, M.D., Adolfo Ley, M.D., Josep Roca, M.D., \\ AND JAIME FERNÁNDEZ-LlaMAZARES, M.D. \\ Departments of Intensive Care and Neurosurgery, and Surgery, and Epidemiology Unit, \\ Hospital Universitario "Germans Trias i Pujol," Badalona; \\ and Universidad Autónoma de Barcelona, Barcelona, Spain
}

\begin{abstract}
The authors conducted a study to determine the value of transcranial Doppler (TCD) ultrasonography in evaluating the outcome of severely head injured patients and to correlate the TCD values with those obtained from intracranial pressure (ICP) and cerebral perfusion pressure (CPP) monitoring.

The authors conducted a prospective study of 125 patients with severe head injury (Glascow Coma Scale scores of less than 9) who underwent TCD ultrasonography according to the standard technique of insonating the middle cerebral artery (MCA) and measuring the mean blood flow velocity and pulsatility index within the first 24 hours of admission. The ICP and CPP values, as well as other clinical, analytical, and neuroimaging data, were also recorded. After 6 months, outcome was evaluated using the Glasgow Outcome Scale. Moderate disability and complete recovery were considered "good" outcome; death, vegetative state, and severe disability were considered "poor."

In 67 patients (54\%) good outcome was demonstrated whereas in $58(46 \%)$ it was poor. The mean blood flow velocity of the MCA in patients with good outcome was $44 \mathrm{~cm} / \mathrm{second}$; in those with poor outcomes it was $36 \mathrm{~cm} / \mathrm{second}$ $(\mathrm{p}<0.003)$. The mean PI in cases of good outcome was 1 whereas in poor outcome was $1.56(\mathrm{p}<0.0001)$. The correlations of ICP and CPP to PI were statistically significant $(\mathrm{r} 2=0.6 ; \mathrm{p}<0.0001)$.

When performed in the first 24 hours of severe head injury, TCD ultrasonography is valid in predicting the patient's outcome at 6 months and correlates significantly with ICP and CPP values.
\end{abstract}

\section{KEY WORDS - transcranial Doppler ultrasonography severe cranioencephalic trauma outcome - pulsatility index - mean velocity • intracranial pressure - cerebral perfusion pressure}

Severe head injury is one of the principal causes of mortality and morbidity in western countries. Annually, between 1 and 1.5 million people suffer severe head injury in the U.S., making it responsible for $60 \%$ of trauma-related deaths and the leading cause of neurological sequelae. ${ }^{13,16}$ The study of outcome in head-injured patients has such importance because it allows us to establish prognostic criteria on hospital admission, determine management needs, evaluate therapeutic advances, increase our knowledge of the pathophysiology of traumatic brain injury, and appropriately adapt rehabilitation programs.

Abbreviations used in this paper: $\mathrm{APACHE}=$ Acute Physiology and Chronic Health Evaluation; CPP = cerebral perfusion pressure; $\mathrm{CT}=$ computerized tomography; GCS = Glasgow Coma Scale; GOS = Glasgow Outcome Scale; ICP = intracranial pressure; $\mathrm{MCA}=$ middle cerebral artery; $\mathrm{PI}=$ pulsatility index; $\mathrm{ROC}=$ receiver operating characteristic; $\mathrm{SAH}=$ subarachnoid hemorrhage; $\mathrm{TCD}=$ transcranial Doppler; TCDB = Traumatic Coma Data Bank.
The precision of scales currently used for traumatic head injury is sometimes thrown off by the frequency with which patients are intubated, sedated, and left paralyzed, thus making clinical evaluation difficult. Many studies have been conducted in which the outcome after severe head injury has been evaluated using the following parameters: 1) clinical findings, such as the profundity of coma as measured using the GCS score, pupillary reactivity, the presence of hypotension, or respiratory irregularities: ${ }^{25,29}$ 2) analytical alterations, such as hypoxemia or anemia; ${ }^{4} 3$ ) lesions observed on CT scanning according to the classification of the $\mathrm{TCDB}^{28}$ or $\mathrm{SAH}^{, 22,26}$ and 4) cerebral monitoring parameters such as ICP $^{27}$ and CPP. ${ }^{30,36}$ Since it was first introduced in 1981 by Aaslid and colleagues, ${ }^{2} \mathrm{TCD}$ (by using 2-MHz probes in certain bone windows) has been performed to measure cerebral blood flow velocity, thus affording an indirect look at the blood flow of the insonated blood vessel.

In addition to its use in evaluating different cerebral pathological entities, TCD ultrasonography has been 
demonstrated to be reliable and useful in acute neurological disorders such as cerebral artery obstruction, ${ }^{3,15}$ vasospasms in spontaneous $\mathrm{SAH}, 1,39$ and the diagnosis of brain death. ${ }^{12,33}$ However, evaluation of its effectiveness in patients with traumatic brain injury, 5,8,9,38 and its correlation with ICP and CPP values, , $7,17-19,24,37,42$ to offer better insight into the outcome of these cases, has been performed in few studies.

\section{CLINICAL MATERIAL AND METHODS}

Our prospective study took place between 1993 and 1998 at the Hospital Universitario Germans Trias y Pujol in Badalona, Spain, a 600-bed reference center for polytraumatic cases in an area of 700,000 inhabitants. One hundred twenty-five patients, all transfered from the emergency room services or extrahospital emergency services admitted to Intensive Care, were included. Inclusion criteria were severe head injury and a GCS score less than 9, the presence of cranial lesions on CT, and hospitalization for more than 24 hours. Exclusion criteria were an inability to perform TCD ultrasonography due to the impossibility of insonating the MCA, the presence of surgical bandage, or soft tissue hematomas; irregularity in the left ventrical ejection volume (due to, for example, fibrillation or auricular flutter, or frequent ventricular extrasystole); and cardiac frequency greater than 140 beats/minute.

We collected the demographic data on age, sex, and mechanism of injury (motorcycle or automobile accident, fall, or struck by a vehicle).

The qualitative variables studied included the presence of associated lesion (thoracic, abdominal, or large-bone trauma); alterations of the size of pupillary reactivity; the presence of neurological focal injury; convulsions or otorrhagia; shock; CT lesions (various Type II and III lesions, according to the TCDB, and presence of SAH); and neurosurgical intervention.

The quantitative variables included patient age; presence of glycemia; arterial gasometry $\left(\mathrm{pH}, \mathrm{PaCO}_{2}, \mathrm{PaO}_{2}\right)$, hemoglobin count, severity according to the APÁCHE II scale; GCS score; ICP measured via an intraparenchymatous catheter (OLM Intracranial Pressure Monitoring Kit, Model 110-4B, Neurocare Group, San Diego, CA); CPP; and the parameters registered using TCD ultrasonography, mean blood flow velocity and PI.

We used a TCD system (Transcranial Doppler EME TC2-64B; Eden Medicinische Elektronik GmbH, Ueberlingen, Germany), insonating the MCA through a temporal window as described by Aaslid and colleagues. ${ }^{2}$ Mean blood flow velocity was registered, and the PI was determined according to the Gosling Index (PI = systolic velocity - diastolic velocity/mean velocity). A value of $45 \pm 10$ $\mathrm{cm} / \mathrm{second}$ was considered normal mean blood flow velocity, and a normal PI $\leq 1$.

Transcranial Doppler ultrasonography was performed within the first 24 hours, immediately after hemodynamic and respiratory stabilization. Correlation between TCD values and CPP and ICP was made within the first 24 hours, at the same time as blood flow velocity was measured.

Patients were treated with analgesic, sedative, and, when necessary, muscle relaxant medication and were mechanically ventilated. Minimum hemoglobin count was main- tained at $10 \mathrm{~g} / \mathrm{L} ; \mathrm{PaCO}_{2}$ between 30 and $35 \mathrm{~mm} \mathrm{Hg}$; and $\mathrm{PaO}_{2}$ greater than $90 \mathrm{~mm} \mathrm{Hg}$. In the presence of intracranial hypertension, the patient underwent mannitol perfusion and discrete hyperventilation $\left(\mathrm{PaCO}_{2} 26-30 \mathrm{~mm} \mathrm{Hg}\right)$. If the ICP proved uncontrollable, barbiturates were administered to induce barbiturate coma. When necessary, vasoactive drugs were given to maintain CPP at greater than $70 \mathrm{~mm} \mathrm{Hg}$, once the volemia had been corrected.

Outcome was evaluated at 6 months posttreatment by using the GOS..$^{20}$ Scores of 1 (death), 2 (vegetative state) and 3 (severe disability) were considered as "poor" outcome; and GOS scores of 4 (moderate disability), and 5 (complete recovery or correct outcome) were considered as "good" outcomes.

\section{STATISTICAL ANALYSIS}

In the bivariate analysis, we used the Student's t-test to compare the mean values of the groups, and the chi-square test to compare ratios or Fisher's exact test when required because of the number of effects being analyzed. Significance was set at $p<0.05$. To evaluate the relation between prognosis and studied variables, we used a logistic regression model, in which we included those variables that were statistically significant in the bivariate analysis. The Hosmer-Lemeshow goodness-of-fit test, in which data obtained in patients whose outcome was observably poor were compared with those that had been predicted, calculating the area under the ROC curve, was used to measure the reliability of the model.

\section{RESULTS}

General characteristics of the patients are presented in Table 1. Oveall 96 (77\%) of 125 patients were men. Brain injury was the result of motorcycle accidents in 37 cases (30 without helmet and 7 with helmet); automobile accidents in 29 cases; falls in 29 cases; being hit by a car in three cases; and other causes in 7 cases.

Associated injuries included 26 cases of thoracic, 34 cases of abdominal, and 17 cases of large-bone trauma. The mortality rate at 6 months was $37 \%$ (46 patients), with brain death occurring in $89 \%$ of them. Table 2 shows the mean values of quantitative variables, and Table 3 shows the qualitative variable results.

In accordance with the GOS score, outcome was defined as good (recovery or moderate disability) or poor (death, vegetative state, or severe disability).

Statistically significant factors in the prediction of outcome at 6 months included: anomalies in pupillary reactivity or size; shock; and Type III lesions (according to the TCDB classification $)^{28}$ with compressed or absent cisterns, 0 to 5 -mm displacement of the midline, and high-density lesions less than $25 \mathrm{ml}$ in volume. Additionally, the presence of SAH was a statistically significant prognostic factor. Quantitative variable results appear in Table 4.

Statistically significant variables in predicting outcome at 6 months were: severity index of APACHE II on hospital admission (an APACHE score of 11 predicted good outcome whereas an APACHE score of 16 indicated a poor outcome); depth of coma as reflected by the GCS score (a GCS score of 7.2 predicted good whereas a GCS 
Evaluating the outcome of severe head injury with transcranial Doppler ultrasonography

TABLE 1

GENERAL DESCRIPTION OF STUDY VARIABLES OBTAINED IN 125 SEVERELY HEAD INJURED PATIENTS*

\begin{tabular}{lc}
\hline \hline \multicolumn{1}{c}{ Characteristic } & No. of Cases (\%) \\
\hline sex male & \\
$\quad$ female & $96(77)$ \\
associated lesion & $29(23)$ \\
pupillary anomalies & $92(74)$ \\
focal injury & $36(29)$ \\
convulsion & $17(14)$ \\
otorrhagia & $7(6)$ \\
cranial fracture & $37(30)$ \\
shock & $52(41)$ \\
CT classification & $35(28)$ \\
$\quad$ Type II lesion & \\
Type III lesion & $82(66)$ \\
SAH & $18(14)$ \\
exitus & $65(52)$ \\
\hline
\end{tabular}

* Classification based on that reported in TCDB.

score of 4.6 predicted a poor outcome); ICP and CPP (mean ICP for good outcome was $15 \mathrm{~mm} \mathrm{Hg}$ and for poor outcome was $30 \mathrm{~mm} \mathrm{Hg}$; CPP indicating good outcome was $71 \mathrm{~mm} \mathrm{Hg}$, whereas the value for a poor outcome fell to $55 \mathrm{~mm} \mathrm{Hg}$ ); and mean blood flow velocity and PI (mean blood flow velocity for good outcome was 44 $\mathrm{cm} / \mathrm{second} ; 36 \mathrm{~cm} / \mathrm{second}$ for poor; PI values showed an even better correlation to outcome, with a PI of 1 indicating good outcome and 1.56 indicating poor).

\section{Correlation Between TCD Values and ICP and CPP}

Figure 1 demonstrates that for each increase of 1 unit in ICP, the PI increased 0.03 units. This increase is statistically significant $(p<0.0001)$ and different from 0 . Intracranial pressure and PI regression are shown in Fig. 1, with an $\mathrm{r}^{2}$ of 0.69 and an equation model of PI $=0.48+$ 0.03 ICP.

Figure 2 demonstrates that for each drop of 1 unit in CPP, the PI increased 0.02 units. This is statistically significant $(\mathrm{p}<0.0001)$ and different from 0 . Cerebral perfusion pressure and PI regression is shown in Fig. 2, with an $\mathrm{r}^{2}$ of 0.61 and an equation model of PI $=2.7-0.02$ CPP.

In the multivariate analysis, the factors of greatest specific value and those least correlated with the rest of the variables, both quantitatively and qualitatively, were GCS score; pupillary reactivity or size; shock; and PI (Table 5). Pulsatility index has important specific weight in predicting patient outcome.

\section{DISCUSSION}

In our study, the overall mortality rate at 6 months was $37 \%$ (46 patients). Overall, 54\% (67 patients) made good outcome (complete recovery or moderate disability), and poor outcome (death, vegetative state, or severe disability) was demonstrated in $46 \%$ (58 patients). These results are
TABLE 2

Mean VAlues obTaINED OF THE QuANTITATIVE VARIABLES STUdied

\begin{tabular}{lcc}
\hline \multicolumn{1}{c}{ Variable } & Mean Value & Standard Deviation \\
\hline age $(\mathrm{yrs})$ & 34.14 & 19.16 \\
$\mathrm{pH}$ & 7.37 & 0.08 \\
$\mathrm{PaCO}_{2}(\mathrm{~mm} \mathrm{Hg})$ & 35.9 & 9.75 \\
$\mathrm{PaO}_{2}(\mathrm{~mm} \mathrm{Hg})$ & 173 & 113.5 \\
hemoglobin $(\mathrm{g} / \mathrm{l})$ & 11.49 & 2.48 \\
glucose level $(\mathrm{mg} / \mathrm{dl})$ & 161.76 & 62.52 \\
$\mathrm{MAP}^{*}(\mathrm{~mm} \mathrm{Hg})$ & 85.86 & 11.45 \\
$\mathrm{GCS} \mathrm{score}_{\mathrm{APACHE} \mathrm{II}}$ & 6.02 & 1.81 \\
ICP $(\mathrm{mm} \mathrm{Hg})$ & 13.68 & 4.34 \\
$\mathrm{CPP}(\mathrm{mm} \mathrm{Hg})$ & 22.07 & 17.29 \\
blood flow velocity $(\mathrm{cm} / \mathrm{s})$ & 63 & 19.70 \\
$\mathrm{PI}$ & 40.75 & 17.86 \\
\hline
\end{tabular}

* MAP = mean arterial blood pressure.

similar to those obtained in other reports published on the subject. ${ }^{25,29}$ Several variables age-sex, presence of associated lesion, neurological focal injuries, convulsions, otorrhagia, neurosurgical intervention, arterial gasometry values, or glycemia - were shown to have demonstrated no statistical significance in relation to poor outcome.

Among the extrahospital factors studied, the GCS score showed significant correlation $(\mathrm{p}<0.0001)$ with patient outcome, as did pupillary size and reactivity $(\mathrm{p}<0.0001)$ and the presence of hypotension $(p<0.0004)$, all of which are already known to be determining factors in outcome after head injury. $10,21,40,41$

The absence of basal cisterns and the presence of SAH are well-defined signs of poor prognosis and outcome. ${ }^{23}$ In our study we demonstrated the correlation between poor outcome and an increase in ICP in those patients with Type III diffuse lesions; in the 18 patients in whom such a lesion was present, $89 \%$ experienced poor outcomes $(\mathrm{p}<$ $0.0001)$. The presence of SAH was also associated with poor prognosis $(\mathrm{p}<0.03)$, which is in line with findings in the bibliographic data. ${ }^{14}$

Of the hospital-related factors analyzed, we found that the severity of patient's condition in the first 24 hours after admission to the intensive care unit, as demonstrated by the APACHE II score, was statistically significant ( $\mathrm{p}<$ 0.0001). This, too, is in accordance with findings published in the literature, ${ }^{24}$ although some authors have found no relation between this variable and severe head injury outcome. ${ }^{11}$

Among analytical values presented on admission, hemoglobin count is important in determining outcome $(\mathrm{p}<0.001)$; in our patients with hemoglobin counts less than $10 \mathrm{~g} / \mathrm{L}$ mortality rate of $60 \%$ was observed.

As has been previously reported, ${ }^{32,34}$ high ICP is associated with higher mortality rates, and such was the case in our study. Likewise, low CPP was associated with poor outcome. ${ }^{35}$

Intracranial pressure value has important predictive power $(\mathrm{p}<0.0001)$. The mean ICP in patients experiencing good outcome was $15 \mathrm{~mm} \mathrm{Hg}$, whereas in those experiencing a poor outcome it rose to $30 \mathrm{~mm} \mathrm{Hg}$. In patients in whom ICP was greater than $40 \mathrm{~mm} \mathrm{Hg}$, the mortality rate was $72 \%$, whereas in those in whom ICP was lower than $20 \mathrm{~mm} \mathrm{Hg}$, the mortality rate was $24 \%$.

In the study of the TCDB,${ }^{27} \mathrm{CPP}$ was shown to have no 
TABLE 3

QUALITATIVE VARIABLES OBTAINED AT 6 MONTHS AFTER INITIAL TCD STUDY

\begin{tabular}{|c|c|c|c|c|c|}
\hline Variable & $\begin{array}{l}\text { No. of } \\
\text { Cases }\end{array}$ & $\begin{array}{l}\text { Percentage } \\
\text { of Good } \\
\text { Outcome }\end{array}$ & $\begin{array}{l}\text { Odds } \\
\text { Ratio }\end{array}$ & $\begin{array}{l}95 \% \\
\text { Confidence } \\
\text { Interval }\end{array}$ & p Value \\
\hline \multicolumn{6}{|l|}{ sex } \\
\hline male & 96 & 52.08 & 1 & & 0.56 \\
\hline female & 29 & 58.02 & 0.77 & $0.31-1.81$ & \\
\hline \multicolumn{6}{|l|}{ associated lesion } \\
\hline yes & 92 & 54.34 & 1 & & 0.56 \\
\hline $\begin{array}{l}\text { no } \\
\text { pupillary reactivity }\end{array}$ & 33 & 51.51 & 1.08 & $0.82-1.42$ & \\
\hline normal & 89 & 70.78 & 1 & & 0.0001 \\
\hline $\begin{array}{l}\text { anomalies } \\
\text { focal injury }\end{array}$ & 36 & 11.11 & 16.74 & $5.83-61.10$ & \\
\hline yes & 17 & 29.41 & 1 & & 0.11 \\
\hline no & 108 & 57.40 & 0.39 & $0.11-1.21$ & \\
\hline \multicolumn{6}{|l|}{ convulsions } \\
\hline yes & 7 & 42.85 & 1 & & 0.81 \\
\hline $\begin{array}{r}\text { no } \\
\text { shock }\end{array}$ & 117 & 54.70 & 0.82 & $0.20-3.90$ & \\
\hline present & 35 & 28.57 & 1 & & 0.0004 \\
\hline $\begin{array}{l}\text { absent } \\
\text { otorrhagia }\end{array}$ & \multicolumn{4}{|c|}{ otorrhagia } & \\
\hline yes & 37 & 51.35 & 1 & & 0.81 \\
\hline no & 88 & 54.54 & 0.91 & $0.41-2.02$ & \\
\hline \multicolumn{6}{|l|}{ CT classification } \\
\hline Type II & 82 & 68.29 & 1 & & \\
\hline Type III & 18 & 11.11 & 17.23 & $4.47-114.17$ & 0.0003 \\
\hline \multicolumn{6}{|l|}{ SAH } \\
\hline present & 65 & 46.15 & 1 & & 0.030 \\
\hline absent & 60 & 61.66 & 0.45 & $0.21-0.94$ & \\
\hline \multicolumn{6}{|l|}{ surgery } \\
\hline yes & 28 & 35.71 & 1 & & 0.62 \\
\hline no & 97 & 58.76 & 1.23 & $0.51-2.94$ & \\
\hline
\end{tabular}

predictive value in the outcome of head-injured patients; however, in more recent studies the investigators have demonstrated the importance of CPP in avoiding ischemic cerebral lesions and improving patient outcome. ${ }^{31}$ In our study CPP values were found to be capable of predicting outcome. In patients who made good outcomes a mean CPP value of $71 \mathrm{~mm}$ HG was demonstrated, which drop- ped to $55 \mathrm{~mm} \mathrm{Hg}$ in patients in whom outcome was poor $(\mathrm{p}<0.0001)$.

Transcranial Doppler ultrasonography values (blood flow velocity and PI), recognized as important in severe neurological conditions-especially in the diagnosis of vasospasm associated with spontaneous aneursymal SAH and in the determination of brain death-demonstrate a high

TABLE 4

QUANTITATIVE VARIABLES OBTAINED AT 6 MONTHS

\begin{tabular}{|c|c|c|c|c|c|}
\hline \multirow[b]{2}{*}{ Variable } & \multicolumn{2}{|c|}{ Mean Value } & \multirow[b]{2}{*}{$\begin{array}{l}\text { Odds } \\
\text { Ratio }\end{array}$} & \multirow[b]{2}{*}{$\begin{array}{l}\text { 95\% Confidence } \\
\text { Interval }\end{array}$} & \multirow[b]{2}{*}{$\begin{array}{c}p \\
\text { Value }\end{array}$} \\
\hline & $\begin{array}{c}\text { Good } \\
\text { Evolution }\end{array}$ & $\begin{array}{c}\text { Poor } \\
\text { Evolution }\end{array}$ & & & \\
\hline age (yrs) & 32.47 & 36.06 & 1.00 & $0.98-1.02$ & 0.38 \\
\hline $\mathrm{pH}$ & 7.38 & 7.36 & 0.03 & $0.0-2.14$ & 0.11 \\
\hline $\mathrm{PaCO}_{2}(\mathrm{~mm} \mathrm{Hg})$ & 35.61 & 36.25 & 1.00 & $0.96-1.04$ & 0.73 \\
\hline $\mathrm{PaO}_{2}(\mathrm{~mm} \mathrm{Hg})$ & 183.91 & 160.79 & 0.999 & $0.996-1.00$ & 0.53 \\
\hline glucose (mg/dl) & 169.31 & 153.05 & 0.99 & $0.98-1.00$ & 0.13 \\
\hline $\mathrm{Hb}(\mathrm{g} / \mathrm{L})^{*}$ & 12.18 & 10.70 & 0.76 & $0.64-0.89$ & 0.001 \\
\hline APACHE II & 11.65 & 16.01 & 1.35 & $1.20-1.54$ & 0.0001 \\
\hline GCS score & 7.22 & 4.63 & 0.25 & $0.14-0.38$ & 0.0001 \\
\hline ICP (mm Hg) & 15.13 & 30.08 & 1.08 & $1.04-1.13$ & 0.0001 \\
\hline CPP (mm Hg) & 71.22 & 55.20 & 0.94 & $0.92-0.97$ & 0.0001 \\
\hline blood flow velocity $(\mathrm{cm} / \mathrm{s})$ & 44.59 & 36.31 & 0.96 & $0.94-0.98$ & 0.003 \\
\hline PI & 1.00 & 1.56 & 8.50 & $3.31-26.60$ & 0.0001 \\
\hline
\end{tabular}

${ }^{*} \mathrm{Hb}=$ hemoglobin. 


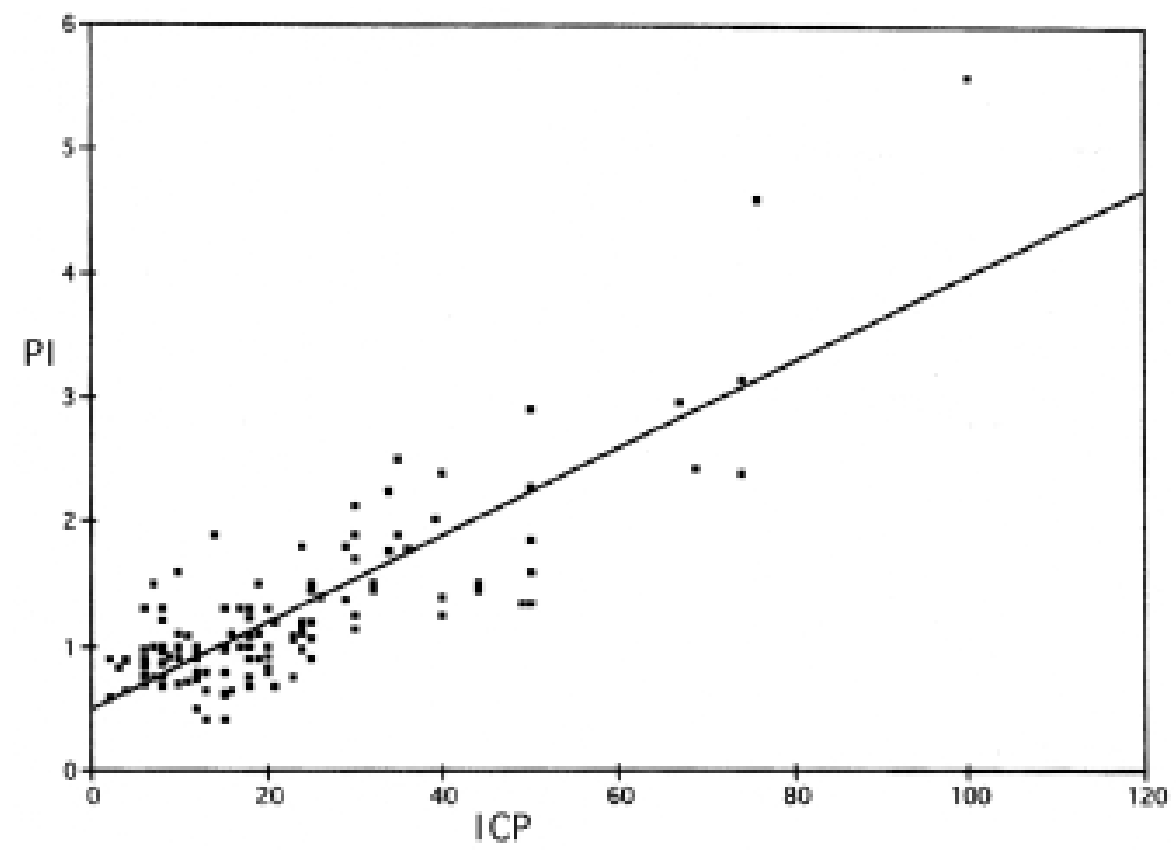

Fig. 1. Graph illustrating the correlation between ICP and PI.

degree of sensitivity in both uni- and multivariate analyses in predicting the outcome of severely brain injured patients.

Mean MCA blood velocity values showed predictive value only in the univariate analysis. Mean blood velocity, as measured in patients with good outcome, was $44 \mathrm{~cm} /$ second, whereas it was $36 \mathrm{~cm} / \mathrm{second}$ in those with poor outcome $(p<0.003)$. We found poor outcome in $71 \%$ of the patients with mean blood velocity less than $30 \mathrm{~cm} / \mathrm{sec}-$ ond, which is a figure similar to that reported by Chan, et al. ${ }^{9}$
The PI was statistically significant in both uni- and multivariate analyses. The mean PI predicting good outcome was 1 , with $71 \%$ of our patients with a PI of less than or equal to 1 making good outcome. The mean PI predicting poor outcome was 1.56 , with $83 \%$ of those with a PI of greater than or equal to 1.56 suffering poor outcome. In cases in which the PI was equal to or greater than 2.3 , the mortality rate was $100 \%$.

We can, therefore, affirm that as is the case with clini-

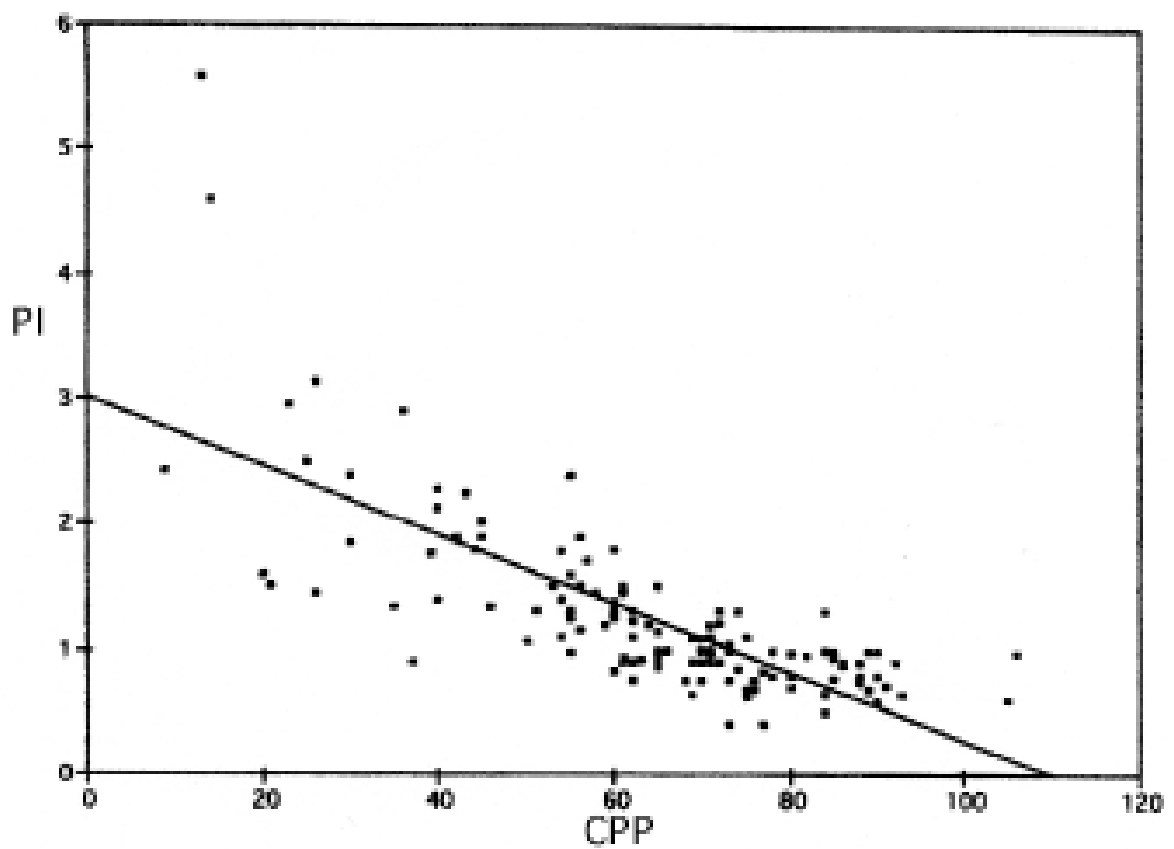

Fig. 2. Graph illustrating the correlation between CPP and PI. 
TABLE 5

RESULTS OF MULTIVARIATE ANALYSIS OF DATA OBTAINED AT 6 MONTHS $^{*}$

\begin{tabular}{|c|c|c|c|}
\hline Variable & Odds Ratio & $\begin{array}{l}95 \% \text { Confidence } \\
\text { Interval }\end{array}$ & $\mathrm{p}$ Value \\
\hline GCS score & 0.24 & $0.11-0.42$ & 0.0001 \\
\hline pupillary anomalies & 3.86 & $0.59-27$ & 0.04 \\
\hline presence of shock & 0.13 & $0.02-0.63$ & 0.013 \\
\hline $\mathrm{PI}$ & 21.42 & $3.81-183.08$ & 0.001 \\
\hline
\end{tabular}

* Hosmer-Lemeshow best-of-fit test of reliability of statistical adjustment, $p=0.9952$. Area below ROC curve $95 \%$.

cal (depth of coma, hypotension), analytical (anemia), and radiological (CT) parameters, as well as those of intracranial monitoring (ICP and CPP), TCD parameters (mean blood flow velocity and PI of MCA), when measured within 24 hours after admission for severe severe head injury, provide reliable insight into the patient outcome; furthermore, measurements are not altered by the effects of patient sedation or relaxation.

The correlation between PI and the ICP and CPP values in our study suggests, but does not prove that TCD ultrasonography evaluation in cases of severe head injury may be a tool in detecting the existence of intracranial hypertension and thus indicate the need for ICP monitoring in some cases of moderate head injury.

\section{CONCLUSIONS}

Transcranial Doppler ultrasonography is a bloodless technique that is easily performed at the patient's bedside to determine the mean blood flow velocity and PI values of the MCA, with no alteration caused if the patient has been sedated. The values obtained in our study demonstrate good correlation between ICP and CPP values and predict outcome in cases of severe head injury. Therefore, TCD ultrasonography should be gradually included in the treatment and management of severely head-injured patients. Although more studies are needed before we can substitute direct measurement of the ICP, change in TCD values may urge us to undertake other diagnostic steps that will improve care and treatment of these patients and predict their outcomes.

In addition, TCD ultrasonography allows us to forecast the patient's evolution after admission in a safe, noninvasive manner. Sedation levels do not need to be modified. This as well as clinical, analytical, and CT parameters will help us to improve human and economical resources involved in caring for these patients.

\section{References}

1. Aaslid R, Huber P, Nornes H: Evaluation of cerebrovascular spasm with transcranial Doppler ultrasound. J Neurosurg 60: 37-41, 1984

2. Aaslid R, Markwalder TM, Nornes H: Noninvasive transcranial Doppler ultrasound recording of flow velocity in the basal cerebral arteries. J Neurosurg 57:769-774, 1982

3. Babikian VL: Transcranial Doppler evaluation of patients with ischemic cerebrovascular disease, in Babikian VL, Wechsler LR (eds): Transcranial Doppler Ultrasonography. St. Louis: Mosby, 1993, pp 87-104
4. Becker DP, Gade GF, Miller JD: Prognosis after head injury, in Youmans JR (ed): Neurological Surgery, ed 3. Philadelphia: WB Saunders, 1990, Vol 3, pp 2194-2229

5. Boishardy N, Granry JC, Jacob JP, et al: [Value of transcranial Doppler ultrasonography in the management of severe head injuries.] Ann Fr Anesth Reanim 13:172-176, 1994 (Fr)

6. Butterworth JE, Prough DH: Head trauma, in Rippe JM (ed): Intensive Care Medicine, ed 2. Boston: Little, Brown, 1991, pp 1459-1477

7. Czosnyka M, Richards HK, Whitehouse HE, et al: Relationship between transcranial Doppler-determined pulsatility index and cerebrovascular resistance: an experimental study. J Neurosurg 84:79-84, 1996

8. Chan KH, Dearden NM, Miller JD: The significance of posttraumatic increase in cerebral mean blood flow velocity: a transcranial Doppler ultrasound study. Neurosurgery 30:697-700, 1992

9. Chan KH, Miller JD, Dearden NM: Intracranial blood flow velocity after head injury: relationship to severity of injury, time, neurological status and outcome. J Neurol Neurosurg Psychiatry 55:787-791, 1992

10. Chesnut RM: Avoidance of hypotension: conditio sine qua non of successful severe head-injury management. J Trauma 42 (Suppl 5):S4-S9, 1997

11. Chesnut RM: Glasgow Coma Score versus severity systems in head trauma. Crit Care Med 26:10-11, 1998 (Editorial)

12. Feri M, Ralli L, Felici M, et al: Transcranial Doppler and brain death diagnosis. Crit Care Med 22:1120-1126, 1994

13. Gentry LR: Imaging of closed head injury. Radiology 191: $1-17,1994$

14. Greene KA, Marciano FF, Johnson BA, et al: Impact of traumatic subarachnoid hemorrhage on outcome in nonpenetrating head injury. Part I: A proposed computerized tomography grading scale. J Neurosurg 83:445-452, 1995

15. Halsey JH Jr: Prognosis of acute hemiplegia estimated by transcranial Doppler ultrasonography. Stroke 19:648-649, 1988

16. Hamill RW, Woolf PD, McDonald JV, et al: Catecholamines predict outcome in traumatic brain injury. Ann Neurol 21: 438-443, 1987

17. Hassler W, Steinmetz H, Gawlowski J: Transcranial Doppler ultrasonography in raised intracranial pressure and in intracranial circulatory arrest. J Neurosurg 68:745-751, 1988

18. Hassler W, Steinmetz H, Pirschel J: Transcranial Doppler study of intracranial circulatory arrest. J Neurosurg 71:195-201, 1989

19. Homburg AM, Jakobsen M, Enevoldsen E: Transcranial Doppler recordings in raised intracranial pressure. Acta Neurol Scand 87:488-493, 1993

20. Jennett B, Bond M: Assessment of outcome after severe brain damage. A practical scale. Lancet 1:480-484, 1975

21. Jennett B, Teasdale G, Braakman R, et al: Predicting outcome in individual patients after severe head injury. Lancet 1: 1031-1034, 1976

22. Kakarieka A, Braakman R, Schakel EH: Clinical significance of the finding of subarachnoid blood on CT scan after head injury. Acta Neurochir 129:1-5, 1994

23. Kido DK, Cox C, Hamill RW, et al: Traumatic brain injuries: predictive usefulness of CT. Radiology 182:777-781, 1992

24. Knaus WA, Draper EA, Wagner DP, et al: APACHE II: a severity of disease classification system. Crit Care Med 13: 818-829, 1985

25. Levati A, Farina ML, Vecchi G, et al: Prognosis of severe head injuries. J Neurosurg 57:779-783, 1982

26. Lobato RD, Sarabia R, Rivas JJ, et al: Normal computerized tomography scan in severe head injuries. Prognostic and clinical management implications. J Neurosurg 65:784-789, 1986

27. Marmarou A, Anderson RL, Ward JD, et al: Impact of ICP instability and hypotension on outcome in patients with severe head trauma. J Neurosurg 75 (Suppl):S59-S66, 1991 


\section{Evaluating the outcome of severe head injury with transcranial Doppler ultrasonography}

28. Marshall LF, Bowers S, Klauber MR, et al: A new classification of head injury based on computerized tomography. J Neurosurg 75 (Suppl):S14-S20, 1991

29. Marshall LF, Gautille T, Klauber MR, et al: The outcome of severe closed head injury. J Neurosurg 75 (Suppl):S28-S36, 1991

30. McGraw CP: A cerebral perfusion pressure greater than $80 \mathrm{~mm}$ $\mathrm{Hg}$ is more beneficial, in Hoff JT (ed): Intracranial Pressure VII. Berlin: Springer-Verlag, 1989, pp 839-841

31. Mendelow AD, Alcutt DA, Chambers LR, et al: Intracranial and cerebral perfusion pressure monitoring in the head injured patient. Which index? in Avezaat CJJ (ed): Intracranial Pressure VIII. New York: Springer-Verlag, 1993, pp 544-548

32. Miller JD, Becker DP, Ward JD, et al: Significance of intracranial hypertension in severe head injury. J Neurosurg 47: 503-516, 1977

33. Petty GW, Mohr JP, Pedley TA, et al: The role of transcranial Doppler in confirming brain death: sensitivity, specificity, and suggestions for performance and interpretation. Neurology 40: 300-303, 1990

34. Resnick DK, Marion DW, Carlier P: Outcome analysis of patients with severe head injuries and prolonged intracranial hypertension. J Trauma 42:1108-1111, 1997

35. Rosner MJ, Daughton S: Cerebral perfusion pressure management in head injury. J Trauma 30:933-941, 1990

36. Rosner MJ, Rosner SD, Johnson AH: Cerebral perfusion pressure: management protocol and clinical results. J Neurosurg 83:949-962, 1995

37. Schmidt B, Klingelhöfer J, Schwarze JJ, et al: Noninvasive pre- diction of intracranial pressure curves using transcranial Doppler ultrasonography and blood pressure curves. Stroke 28: 2465-2472, 1997

38. Shigemori M, Kikuchi N, Tokutomi T, et al: Monitoring of severe head-injured patients with transcranial Doppler (TCD) ultrasonography. Acta Neurochir Suppl 55:6-7, 1992

39. Sloan MA, Haley EC Jr, Kassel NF, et al: Sensitivity and specificity of transcranial Doppler ultrasonography in the diagnosis of vasospasm following subarachnoid haemorrhage. Neurology 39:1514-1518, 1989

40. Vilalta J, Vaqué J, Olona M, et al: [Predictive factors of mortality in severe craniocerebral trauma.] Med Clin 99:441-443, 1992 (Sp)

41. Winchell RJ, Simons RK, Hoyt DB: Transient systolic hypotension. A serious problem in the management of head injury. Arch Surg 131:533-539, 1996

42. Yoshida A, Shima T, Okada Y, et al: Relationship between cerebral perfusion pressure and pulsatility index of transcranial Doppler sonogram, in Avezaat CJJ (ed): Intracranial Pressure VIII. New York: Springer-Verlag, 1993, pp 332-337

Manuscript received September 1, 1999.

Accepted in final form December 12, 1999.

Address reprint requests to: José A Moreno, M.D., Servicio de Medicina Intensiva, Hospital Universitario "Germans Trias i Pujol," 08916 Badalona. Spain. email: 9466jam@comb.es. 